\title{
ALMANZOR, UN HÉROE ANDALUSÍ
}

\author{
$M^{a}$ Eugenia Gálvez Vázquez
}

\begin{abstract}
In this article we try to reveal how certain historic characters overcome the frontiers of strict history and accede to the world of heroes becoming a legend, because of their bright personality and the facts that meet together in their own lives. Thereby we beliefe this is exactly what occurs to the figure of Almanzor, the great state-man and warior who lived in the final years of the califal Cordoba. Regarding to a pair of remarcable studies from the past century like: Almanzor, an Arab Legend, by F.J. Simonet (1829-1897), and History of Muslim Spain, by R. Dozy (1820-1883), we present the historic figure of this character wich life, is deeply joined to the manoeuvres de Palais, great deeds and nameless love affairs as a mythical hero. This fame spreads the limits of Al-Andalus reaching the christian Spain and being shaped by the cronichles, ballads and legends. From wich we specificly refer to the Traitress Countess Studied by R. Menéndez Pidal.
\end{abstract}

"Vencer la muerte es, pues, vivir en la memoria". (Emilio Lledó: Memoria de la ética.)

\section{Introducción}

Concebimos como héroe a aquel personaje que por sus acciones valerosas trasciende su validez histórica de modo que su personalidad se hace desmesurada en lo bueno y en lo malo. Si valiente, el más valiente, si cruel, el más cruel, si generoso, el que más.

Entonces el héroe alcanza unos perfiles especiales que se van configurando con el paso del tiempo, transmitiéndose al principio su fama de forma oral y sometiéndose unas veces consciente, otras inconscientemente a la elaboración poética, formando una masa viva de leyendas que se renueva sin cesar y que también sin cesar sufre nuevas transformaciones.

Para Vedel ${ }^{1}$ la tradición crea un determinado concepto a partir del cual los rasgos del héroe adquieren un sello más relevante, destacándose de forma más idealista y viva la sobria realidad histórica.

En la tradición legendaria todo se depura y se sublima, diluyendo lo accidental y destacándose lo esencial. La leyenda siempre es grandiosa porque la pacífica vida cotidiana se soslaya y se olvida. El héroe es un personaje siempre de punta en blanco y que parece no estar sometido a la bajas leyes de la naturaleza humana. Los elementos que lo rodean también son perfectos: si hay damas, serán hermosas y bellamente acicaladas, si hay pajes, delicados, graciosos y etéreos; si se trata de malvados, los más pérfidos que mente humana pueda concebir.

${ }^{1}$ W. Vedel: Ideales de la Edad Media (Barcelona 1929) I. p. 38-39 
El aspecto físico y el vigor son muy importantes en el héroe, así como su aptitud guerrera. Sus armas adquieren personalidad propia y lo mismo ocurre con su montura (Scalibur, Babieca, etc.). Otra de sus caracetrísticas es el amor a una dama que encarna en grado óptimo todas las perfecciones o todos los defectos, según el papel que realice con respecto al héroe, pero nunca va a ser anodino y vulgar. Esta dama será dueña de sus pensamientos y anhelos, y no descansará hasta conseguirla.

Según $V_{\text {edel }}^{2}$ las caractrísticas principales del héroe serían: la avaricia, la fiereza, la firmeza, el afán de superación, la tenacidad y el cumplimiento de las promesas heróicas.

Las gestas medievales encontraron gran eco en el Romanticismo, y así se revivieron vidas de personajes o acciones históricas. El concepto romántico trasciende también a los historiadores que no son ajenos a la exaltación que anida en el ánimo de todos los que vivieron esta época.

Nada por tanto más lógico que el mundo árabe, hispano-árabe y la reconquista cristiana fueran acometidos por los especialistas de dicha época con tintes de epopeya y fanfarria heróica. Ello tienta al historiador que se siente inclinado, a veces inconscientemente otras no, a recrear los personajes y los hechos basándolos en lo científico, pero escenificándolos con la parafernalia más fabulosa.

No olvidemos que junto al movimiento romántico en el estricto sentido literario, surge en Europa el concepto de las nacionalidaes, y que cada país indaga en sus propias raíces reviviendo todos los momentos gloriosos de la nación. Por ello, cuando Reinhart Dozy acomete su Historia de los musulmanes de España (1861), lo hace movido por el deseo de rectificar la Historia de la dominación de los árabes en España de Conde, plagada de errores, pero también impulsado por el deslumbramiento que esa parte de la Historia de España le produce. Y parece que fuera un impulso romántico lo que llevó a Simonet a escribir su Almanzor, una leyenda árabe que formó parte de una colección titulada Leyendas históricas (1850).

Lo que acabamos de exponer sobre estos dos eximios arabistas no merma en lo más mínimo su extraordinaria labor de investigación, labor que realizaron a lo largo de una vida científica llena de aciertos. Sólo queremos resaltar que ambos se vieron inmersos en esa corriente romántica que plasmaron en las obras citadas, en las que nos vamos a basar para definir la personalidad de nuestro héroe: Ibn Abi Amir, Almanzor.

\section{Almanzor, el retrato de un héroe}

Simonet lo describe así:

"Muhammad Abu Amir ha realzado la aventajada y majestuosa presencia de su padre Abu-Allah, con cierta gracia y aspecto seductor de su madre Foraiha. En cuanto al las dotes del alma conocido es por sus mismos hechos la superioridad y grandeza del corazón con que emprende y ejecuta las cosas más arduas, poniendo en todos sus negocios extraordinaria atención, constancia y empeño, y dirigiéndolos por sí mismo, por muchos, graves y espinosos

${ }^{2}$ W. Vedel: Ibid. I, p.97-98 
que sean. Mas si en lo tocante al gobierno es sobremanera laborioso e infatigable, adonde atiende con mayor celo y diligencia, alcanzando lauros más envidiables, es a las cosas de la guerra, así en los aprestos y marchas para las gazúas, como en ordenar las batallas y demás trances en la yihad. ${ }^{3}$

Varón adornado de altas dotes, religioso, liberal, esforzado, sabio, sagaz, gran capitán, gran hombre de gobierno; pero también ambicioso, disimulado, artero, rapaz, cruel y falto de sentimiento de verdadero cariño y ternura. ${ }^{4}$

Podemos reconocer en este texto todas las dotes que, según Vedel deben adornar a un héroe. Nada falta ni sobra y de este modo contemplamos a nuestro personaje introducido en ese mundo, no sólo desde la óptica musulmana, sino también, como veremos en su momento, en la cristiana.

No es esta una descripción fruto de la imaginación de Simonet, sino que corresponde al autor árabe Abd al-Wahid al-Marraskusi, ${ }^{5}$ y así lo cita nuestro arabista, pero, lo mismo que hará Dozy, ésta quedará enmarcada dentro de un ámbito novelesco y retórico del que ambos autores hacen uso en sus obras citadas.

\section{Almanzor y Subh}

Los primeros puestos de relieve los alcanza Almanzor gracias a la protección de Subh (Aurora), esposa de Al-Hakam II. Simonet dice citando a Al-Maqqari (I, 259) que ésta favoreciéndole con ricos heredamientos en Sevilla, y con el señorío de algunos lugares, le dio nobleza y autoridad y le colmó en fin de tales recompensas y honores, como jamás los obtuvo persona alguna de su servidumbre.

Con tal valimiento y tales prendas, rápidos por demás fueron los ascensos de Muhammad (Almanzor), elevándole el califa por recomendado de la sultana, de uno en otro puesto hasta los más encumbrados", (como inspector de la casa de la moneda, secretario del tesoro y de la oficina de herencias, juez de Sevilla y Niebla, jefe del ejército del Algarve. etc.). ${ }^{6}$

A los 26 años es nombrado intendente de los bienes del primogénito de Al-Hakam II, y por decisión de la sultana Subh, vascona de nacimiento que se sintió atraída por su buena presencia y la distinción de sus maneras. ${ }^{7}$

Su carrera en la corte es vertiginosa de la mano de Subh: intendente de los bienes de la sultana, inspector de la casa de la moneda, etc. Al mismo tiempo se granjeó amigos con su incomensurable generosidad. Pero sobre todo se dedicó a satisfacer todos los caprichos de Subh. Su intimidad fue grande y dio lugar a muchas habladurías y fue acusado ante el califa por malversación. Pero consiguió salir airoso de ello y ganarse aún más la confianza de al-

\footnotetext{
${ }^{3}$ F.J. Simonet: Almanzor, una leyenda árabe. (Madrid, 1986), p. 29-30

${ }^{4}$ F.J. Simonet: Ibid. p.42

${ }^{5}$ F.J. Simonet: Ibid, p. 44-45.

${ }^{6}$ F.J. Simonet: Ibid p. 100

${ }^{7}$ R. Dozy: Historia de los musulmanes en España (Madrid, 1946) p. 136-137, vol III
} 
Hakam II, continuando en su fulgurante carrera de tal manera que, a los 30 años ostentaba ya seis cargos tan importantes como lucrativos.

Cuando muere al-Hakam II, y, tras una serie de sórdidos manejos, Hixam II es aceptado como califa, Ibn Abi Amir es promovido al cargo de visir por orden expresa de la sultana Subh para hecerse cargo de los asuntos de gobierno hasta que el califa niño adquiera la mayoría de edad, responsabilidad compartida con otro poderoso personaje, Mudafi. Ibn Abi Amir, que no era hombre para compartir nada, se dedica a malponer a su compañero en el gobierno ante Subh y consigue de ésta que nombre a Gálib gobernador de la frontera inferior, jefe de la administración civil y militar y generalísimo de todo el ejército de la frontera. Tiene entonces lugar su primera campaña militar, y antes de emprender la segunda, Ibn Abi Amir es nombrado generalísimo del ejército de la capital. Esta campaña la compartió con Gálib, dándose cuenta finalmente Mudafi de dónde partía la traición, decidió pedir en matrimonio para su hijo a Ismá hija de Gálib; pero percatándose Ibn Abi Amir de estos manejos consigue deshacer la jugada y casarse con Ismá.

Fijémonos en el párrafo que sigue, pues aquí vamos a ver una discrepancia entre los hechos escuetos narrados por Dozy, y toda la novelesca y sugerente historia que Simonet nos propone. El texto de Dozy dice así: Aunque este matrimonio se hizo por interés, fue, sin embargo, dichoso. Ismá juntaba un espíritu muy cultivado a una belleza atractiva, y supo cautivar el corazón de su esposo, que le dió siempre la preferencia sobre las demás mujeres. ${ }^{8}$

\section{Retrato de Ismá}

Simonet describe así a la esposa de Almanzor tal como la hemos hallado en un autor árabe (sic) del que no cita la fuente, en contra de su costumbre. ¿Fantasía romántica? ¿invención?

La naturaleza, pródiga de sus encantos con Isma, la había dotado de un cuerpo esbelto, flexible y gentil, que se movía con gracia como la rama de ban, de una voz armoniosa como los suspiros de la brisa en un bosquecillo de palmeras o como el murmullo de una fuente en medio del silencio de la soledad. Su rostro fresco, blanco y sonrosado asombra entre su copiosa y negra cabellera como la aurora cuando rompe las tinieblas de la noche. Pero al adornar en este solemne día su frente virginal y sus torneados cuello y brazos, con sartales y ajorcas de preciosas perlas, su bellísimo semblante asemejaba a la luna cuando en una noche serena aparece rodeada de un séquito de brillantes astros. Realzaba la hermosa doncella su airoso cuerpo con una marlota de Damasco verde labrado de oro, colgaba de sus torneados hombros una ancha y flotante amruna bordada de flores de brillantes matices y medio velaba su rostro un cambuz de finísimo cendal con que semejaba a la luna cuando asoma apenas entre los pliegues de transparente nube. ${ }^{9}$

\footnotetext{
${ }^{8}$ F.J. Simonet: Ibid, p. 20

${ }^{9}$ R. Dozy: Ibid, p. 179-183, vol III
} 


\section{El odio de Subh.}

Pero no siempre fue Subh la fiel amante y favorecedora de Almanzor. Con el paso de los años, la ambición de este caudillo fué en aumento. A los veinte años de gobernar Córdoba como señor absoluto de hecho, aunque no de derecho, la misma mujer que lo encumbró casi consigue derrotarlo. Esta ambición de poder trocó en Subh el amor en odio y, temiendo por el trono de su hijo, resolvió poner en contra de Almanzor a todo el Harén, solicitando por una parte al joven Hixam que se impusiera a su visir, y por otra aliándose con el virrey de Mauritania, Ibn Atiya, único hombre al que el hayib cordobés tenía verdadero miedo. Aurora sabía que su arma era el dinero y así lo hizo llegar al mauritano. Sin embargo Almanzor no se amedrentó. Usó sus artes de persuasión con el califa y consiguió de él un documento por el cual depositaba en su persona toda su confianza. Éste se dio buena maña de difundirlo. Para confirmar los deseos del califa, lo hizo montar a caballo y pasear por las calles de Córdoba acompañado de él y de toda su corte. El peligro estaba conjurado: Subh se dio por vencida y, humillada, buscó consuelo en las obras pías hasta su muerte. ${ }^{10}$

Por otra parte, la fama de Almanzor traspasa las barreras musulmanas y se adentra en la vida de los cristianos, dando lugar a la leyenda de La condesa tridora, sobre la que Menéndez Pidal publica un interesante ensayo, partiendo de las leyendas de Garci Fernández y de su hijo Sancho García. ${ }^{11}$

También desde esa otra orilla de la historia, la figura de Almanzor se ve involucrada en la vida de dos infantas castellanas.

\section{Mujeres y política en Almanzor}

"Una de las características más distintivas de Almanzor creo que ha de ser la de haberse servido siempre en su carrera de mujeres: primero acercándose a las señoras influyentes, como cualquier otro vulgar ambicioso, y después, de modo más particular, para sus fines políticos. En los comienzos se encumbró buscando el favor dentro del Harén del califa Alhakem II, con asiduas finezas, por medio de fabulosos obsequios, el apasionado amor de la sultana favorita, la vascona Aurora (Subh). El viejo califa, cándidamente asombrado, decía a uno de sus íntimos: 'ni sé con qué habilidad este joven capta el corazón de todas mis mujeres, ellas no aprecian mis regalos, no gustan sino de los que él les ofrece; ¿es un servidor inteligente o un mágico hechicero? Y la magia del inteligente servidor dio mucho de que hablar a los cordobeses. Después respecto de los reyes enemigos, descubrimos que también Almanzor utilizó las damas cristianas; sabemos que en 980, viendo como Almanzor llegaba victorioso hasta muy adentro de Castilla, salió al encuentro de él el rey de Navarra, Sancho Garcés, y le hizo ofrenda de su hija. Almanzor la aceptó gustoso, la tomó por mujer y ella islamizó con islamismo excelente, siendo de las mujeres del ministro de las mejores en religión y hermosura. (Es la madre de Abd al-Rahmán Sanchol) [...]

\footnotetext{
${ }^{10}$ R. Menéndez Pidal: "Realismo de la epopeya española. Leyenda de la condesa traidora". Idea imperial de Carlos V (Madrid 1971) p. 37-72.

${ }^{11}$ R. Menéndez Pidal: Ibid, p.59-63.
} 
Hallamos otro caso semejante, del que nos da noticia Ibn Jaldún: en 993 el rey Vermudo II de León, acosado por las incursiones de Almanzor [...] envió a su hija Teresa al caudillo musulmán, el cual la recibió por esclava y después la emancipó para casarse con ella. [...] Una diferencia entre estos dos hechos análogos: mientras la princesa navarra islamizó de todo corazón, la infanta leonesa conservó su cristianismo, pues según la ley musulmana, el marido no tenía derecho a exigir la conversión de su mujer. [...] Teresa, al morir Almanzor, volvió a León, donde tomó el hábito monacal en el convento dedicado a San Pelayo, el muchacho mártir, cuyos lugares de pasión, en Córdoba, ella había venerado.

Esta entrega de princesas, que a la vez que satisfacían el orgullo personal y la sensualidad del invencible caudillo, servían como rehenes, bien es verdad que no impidieron que se renovase la guerra entre Almanzor y sus suegros por fuerza, Sancho de Navarra y Vermudo de León". ${ }^{12}$

\section{Retrato de Elvira}

"Elvira, la hija del señor, (D. Rodrigo González) aunque apenas entrada en la juventud, era ya notable por las gracias de su persona, y más todavía por la extrema discreción y virtud con que formaba el encanto de su buen padre, e inspiraba admiración a cuantos la conocían. Puesto que dotada de extraordinaria hermosura, era su aspecto triste y melancólico, como el de una cristiana orando en las catacumbas en los primeros tiempos del cristianismo. Por lo delicado y esbelto de su persona, por la dulcísima expresión de ternura, que acentuaban sus ojos azules y su rostro pálido, pero de purísimas líneas, y por cierto encanto celestial que aparecía en toda ella, más bien semejaba un ángel, cual suelen presentarlos ciertas pinturas cristianas, que no criatura terrena". ${ }^{13}$

\section{El hilo de la historia de Ismá y Elvira.}

Y como si de una auténtica novela se tratase, el destino hace que la vida de estas dos mujeres se entrecruce. Es como si la leyenda suplantase a la historia, y parte de estos hechos reales se ven alimentados por la narración oral y más adelante por la escrita. De hecho la historia queda elevada a categoría de mito en el que las pasiones se desencadenan.

Ibn Abi Amir, prometido a la joven Ismá, ha oído hablar de las prendas y belleza de una doncella cristiana hija de Don Rodrigo González. Durante su boda con Ismá recibe el recado de que este caballero ha sido nombrado alcaide de Salamanca. Hace caso omiso de los festejos que se están celebrando y abandona a Ismá organizando una gazúa contra Salamanca para conseguir el amor de Elvira, (O Geloira), que así se llamaba la joven, en el año 367 hégira (=977 Jc.). Ante el temor que suscita su presencia en tierras salmantinas, le salen al encuentro dos caballeros cristianos que le dan entrada furtiva en la ciudad para conocer el estado de las fortificaciones y llegar a la casa de Elvira, acompañado de un grupo de caballeros.

\footnotetext{
${ }^{12}$ F.J. Simonet Ibid, p.72

${ }^{13}$ F.J. Simonet: Ibid, p. 73-74.
} 
Ibn Abi Amir entra y sorprende a Elvira en su casa, le cuenta que la ciudad está en manos de los musulmanes, pero que ella se salvará si accede a su amor y a escaparse con él:

"Yo te daré para morada, le dice, alcázares entre jardines, y te rodearé para hacerte feliz de todas las delicias y bienes de la tierra, que eso y más te daré mi amor.

Y yo, respondió resueltamente Elvira, antes me dejaré matar bajo este techo paterno, pues muriendo mártir alcanzaré las delicias y bienes del cielo, únicos que debo codiciar como cristiana.

He caminado ochenta leguas -responde el caudillo-, y aún caminaría ochenta mil por venir a buscarte, pero con tal resolución y acompañamiento de hueste tan numerosa, que no hay plaza fuerte en estos reinos que yo no combatiría y expugnaría hasta encontrarte y llevarte conmigo"14

Elvira está a punto de sucumbir ante el poder de esa pasión y su encanto y dominio personal. Pero recapacita como cristiana virtuosa y lo rechaza.

Cuando sus caballeros están a punto de arrebatarla por la fuerza, entra precipitadamente en la estancia una mujer disfrazada con traje cristiano que no es otra que Ismá que ha seguido Ibn Abi Amir y lo alerta de que parte de sus acompañantes han sido descubiertos en la ciudad y que a él lo andan buscando. Elvira, aliviada, les ayuda a escapar. Este fracaso enciende más en Ibn Abi Amir el deseo de apoderarse de la cristiana, por lo que decide poner sitio a Salamanca, ante la resistencia de Don Rodrigo.

El caudillo musulmán entró y saqueó los arrabales de Salamanca, ganó dos castillos fronterizos e hizo muchos daños. Por fin, levanta el sitio y vuelve a Córdoba.

En el 730 h. (=980-1 J.C.) muere Gálib al-Násir, padre de Ismá, por manejos de Ibn Abi Amir, aunque ella nunca creyó que su marido fuera el culpable de su muerte, y ese mismo año se inaugura Madinat al-Zahira con asistencia del propio califa Hixam II. Con esto, se afianza el poder del visir.

Aunque Ibn Abi Amir en esta época se ocupó de afirmar su poderío en Córdoba, no olvidó por ello sus campañas de armas, ni había olvidado su fracaso con la cristiana Elvira. Don Rodrigo González había pasado en el 981a gobernar Zamora y allí dirige Almanzor sus huestes poniéndole cerco. El acceso a esta ciudad era muy difícil, pero en este momento histórico Galicia se había levantado contra León, y ello creó problemas de falta de ayuda y apoyo al caudillo musulmán. En todo caso, éste no consiguió vencer la resistencia de los zamoranos y resolvió aplazar la empresa para otra campaña, emprendiendo la vuelta a Córdoba donde fue aclamado con el sobrenombre de Al-Mansur, Almanzor (el victorioso y también el ayudado por Dios). Se le dio también el título de malik (rey) y se acuñó moneda con su nombre, pronunciándose éste en las preces de la aljama junto al del califa.

El prestigio militar de este caudillo va creciendo más y más, sobre todo después de su incursión en la marca superior en el 985, adueñándose de Barcelona, y con la expedición a Galicia en ese mismo año.

\footnotetext{
${ }^{14}$ F.J. Simonet: Ibid, p. 162-163.
} 
Pero Almanzor tenía hincada la espina de Zamora agudizando su interés el deseo de conseguir a la cristiana Elvira. Así pués, preparó una nueva campaña contra la ciudad saliendo de Córdoba en el año 986. La sitió, al tiempo que varios escuadrones talaron los contornos y detruyeron lo poco que quedaba en pie después de la última incursión. La resistencia fue grande, pero finalmente Almanzor se apoderó de Zamora y entrando vencedor en la plaza, se encuentra con que Doña Elvira y su padre, con un grupo de caballeros cristianos, habían huido a León.

Almanzor juró que haría otra gazúa contra la corte y mientras, ciego de rabia, hizo enorme estrago en Zamora.

\section{La condesa traidora ${ }^{15}$}

Por el 989 hostigó Castilla con gran insistencia impulsado también por el conde D. Vela, señor de Nájera y Álava, para que acometiese al conde García Fernández, marido de $\mathrm{D}^{\mathrm{a}}$ Sancha, protagonista de la leyenda-historia de La Condesa Traidora.

El conde castellano se vió tan apurado que, temiendo por los suyos no tiene más remedio que, entregarle a Almanzor al príncipe Abd Allah, su hijo que, habiéndose rebelado contra él, se había acogido a la protección del conde de Castilla. Almanzor lo mandó ejecutar sin piedad en las riberas del Duero.

En los años 994 y siguientes Almanzor dirige su ejército con éxito contra Castilla y León.

La campaña contra Castilla es la narrada en la historia de La Condesa Traidora, a resultas de la cual García Fernández, muere en Medinaceli por las heridas que le causaron en dicha campaña cuando es trasladado a Córdoba como prisionero de Almanzor.

En el 996 decide atacar León dónde se encuentra refugiada la inasequible Elvira. Cercada la ciudad estrechamente durante casi un año, la conquistó, salvándose Don Rodrigo; pero Almanzor consigue apresar a Elvira como el trofeo más preciado de su historia.

Vuelto a León tras su doble conquista, instala a Elvira en el palacio de la Amiría, sin que todos los halagos que le prodigaba el gran caudillo le hicieran cambiar de actitud.

Dos personas mientras tanto estaban pendientes de sus movimientos. Por una parte Don Rodrigo, inquieto ante la suerte que hubiera podido correr su hija. Y por otra, Ismá, celosa de la pasión que la joven había despertado en Almanzor.

Así pues decide entrevistarse con Elvira, y por ella sabe que Almanzor no es correspondido y que nada tiene que temer en ese sentido. Convertidas en amigas Ismá pone en contacto a Elvira con la comunidad mozárabe cordobesa para que pueda realizar sus prácticas religiosas y promete ayudarle en todo.

\footnotetext{
${ }^{15}$ R. Menéndez Pidal: "Realismo de la epopeya española. Leyenda de la Condesa traidora", en Idea Imperial de Carlos V, pp.: 39-72.
} 
Almanzor sigue insistiendo en su amor, pero Elvira lo rechaza alegando que se ha ofrecido a Dios. Ante esto el caudillo musulmán, ciego de ira y con deseos de plastar a ese Dios que es su rival, decide emprender la cuadragésimo octava de sus gazúas contra los últimos confines de Galicia en dónde todavía muslim alguno puso planta en un templo frecuentado hasta ahora por peregrinos no sólo de Afranch (Europa) sino hasta de Egipto y Nubia. Reúne un ejército por tierra y organiza su armada, saliendo de Córdoba el 8 de Julio de 977. Llega a Zamora mientras la armada navega desde el Algarve, entra por el Duero y desemboca en su orilla izquierda a la altura de Castel Melhor uniéndose al ejército de tierra. En su avanzada somete varias plazas de Portugal y Galicia antes de dirgirse a Compostela, pasándolo todo a sangre y fuego. Una vez conquistada la ciudad, se encamina directamente al templo del Apostol Santiago, entrando en él montado en su caballo con idea de llegar a la capilla donde se encontraba el sepulcro. Pero Dios le envió un rayo que detuvo a su montura y, comprendiendo que se trataba de una aviso divino postróse rendidamente ante el venerable sepulcro, implorando el perdón de Allah, y para preservarle del desacato y profanación de los suyos, puso soldados que le guardasen. ${ }^{16}$

Narraciones en términos más o menos similares se recogen en la Historia Compostelana, que relata la peste que envió Dios a los musulmanes por haber profanado el templo, a causa de la cual tuvieron que abandonar la ciudad. También el Bayan al-Mugrib (II,319) ofrece una curiosa:

"Cuando el hayib Almanzor entró en la ciudad, esta estaba vacía. Sólo encontró a un anciano ermitaño sentado en el sepulcro del apostol. Almanzor le preguntó que quién era, y él le respondió que un familiar de Santiago. Entonces el caudillo ordenó que, por respeto a su antepasado, no se le hiciera daño.

Sin embargo, después de tan gran hazaña, Almanzor quiso dar algún testominio fehacinte de ella, así que mandó descolgar las campanas menores del santuario que, a hombros de esclavos cristianos, fueron llevadas a la mezquita aljama cordobesa para servir de lámparas. También se llevaron las puertas de Santiago que, en la misma aljama se clavaron de las vigas como trofeo". ${ }^{17}$

Hemos aludido a la población mozárabe que existía en Córdoba en la que florecía una cultura notable. Pues bien, la princesa Ismá, en su afán de ayudar a Elvira y así librarse de ella, consigue que Don Rodrigo sea acogido por esta comunidad mientras Almanzor se hallaba en la campaña de Santiago de Compostela, ocasión que aprovecha el caballero cristiano para organizar una sublevación y dar muerte al hayib. Este alzamiento debía tener lugar a la vuelta de Almanzor de su campaña, aprovechando tanto el descontento interior como lo diezmado del ejército víctima de una epidemia de peste.

La conjura parecía bien urdida pero de nuevo el amor de Ismá por Almanzor pudo más que toda la libertad que ella había concedido a los mozárabes cordobeses, Así pués mandó un emisario a su marido poniéndole en guardia de lo que se tramaba contra él. De este modo fue hecho prisionero D. Rodrigo González, portador de una comprometida misiva a los cristianos rebeldes. Las represalias fueron tremendas. Elvira, que teme que su padre

\footnotetext{
${ }^{16}$ Historia Compostelana. Edición E. Falqué (Turnholt, 1988)

${ }^{17}$ R. Dozy: Ibid, p. 193, vol.III.
} 
haya corrido la peor suerte, pregunta a Almanzor por su vida. Este que no está seguro de su situación, toma a Elvira en sus brazos y en su propia yegua se la lleva con el deseo de remediar lo irremediable: a las puertas del palacio de Medina al-Zahira su cabeza está expuesta junto con la de otros cristianos.

Elvira cae fulminada y ya no regresa de su mortal sueño.

A partir de este suceso Almanzor no vuelve a ser el mismo y arrastra su melancolía.

Sin embargo aún se dan algunos hechos notables en su vida. La Crónica General relata la singular historia de Mudarra González vinculada al episodio de los Siete Infantes de Lara, hechos todos recogidos en nuestro romancero.

A la vuelta de la campaña de Compostela, Almanzor armó caballeros a varios miembros de su ejército emparentados con él. Entre ellos se encontraba un joven llamado Mudarra González, hijo de Gonzalo Gustios y de una hermana de Almanzor. Gonzalo Gustios era un caballero castellano, padre de los siete infantes de Lara, famosos por su trágica muerte a manos de los moros por medio de una carta engañosa. Ruy Velázquez envió a Córdoba a Gonzalo Gustios con idea de que sea muerto por Almanzor; pero como eran grandes amigos, éste no lo ejecuta sino que lo encarcela. La hermana del hayib lo ve y se enamora de él tomándolo a su cargo durante el encierro. De estos amores nace un niño al que los musulmanes llamaron Mudarra y él, en memoria de su padre, tomó el nombre de González. Gustios recobró la libertad y se volvió a Castilla, siendo el niño educado por su madre, teniendo desde muy pequeño gran inclinación por las armas.

Pronto empezó a sentir el deseo de vengar a su padre y a los infantes, sus hermanos; así pués pide a Almanzor permiso para ir a Castilla. Lo consiguió y allí fue con un gran séquito encontrándose con su padre, vengando a sus hermanos y dando muerte a Ruyz Velázquez. En este personaje tuvo origen el linaje de los Manrique.

\section{Muerte del héroe.}

La carrera de Almanzor tocaba a su fín, y en la primavera del 1002 hizo su última expedición. Como un dato más, a la vez curioso y novelesco, hay que reseñar que siempre deseó morir en campaña y cuando salía a guerrear nunca olvidaba su mortaja. Había sido cosida por sus hijas empleando para su compra dinero que provenía de su antiguo castillo de Torróx, pues lo quería limipio de todo lucro. También, cada vez que volvía de una gazúa sacudía cuidadosamente el polvo de sus vestiduras y lo guardaba en un cofre hecho con ese fin, para que cuando muriera se cubriera con él su tumba: ésta sería su justificación ante el Tribunal Supremo, el testimonio de haber muerto en guerra santa.

Mandaban las tropas cristianas el rey Sancho de Navarra y el conde Sancho García. Las fuerzas estaban muy equilibradas, pero al contrario que en otras ocasiones, los cristianos resistieron y causaron gran mortandad. La batalla duró hasta entrada la noche, en que los musulmanes se retiraron.

Almanzor, malherido, se encontraba en su tienda donde tuvo noticia de su derrota. Al amanecer, y ya transportado a hombros en una especie de palanquín durante catorce días, 
llegaron a Medinaceli donde murió, siendo enterrado en este lugar. En su tumba se grabaron estos versos:

"Las huellas que ha dejado en la tierra te enseñarán su historia como si la vieras con tus mismos ojos".

“(Por Allah! que jamás los tiempos traerán otro que se le parezca, ni que como él defienda nuestras fronteras". (Maqqari I, 259). ${ }^{18}$

Había realizado 52 campañas.

\section{Conclusión.}

Vemos pues, que la historia ha sido desbordada ante el cúmulo de aventuras, luchas, amores y odios que concurren en el personaje, y que éste trasciende también su realidad para formar parte del mundo de los héroes.

Las pasiones desatadas en el marco histórico corren de boca en boca para quedar más tarde plasmadas en las crónicas, en las leyendas y en los romances. Pero vemos también que el héroe, aunque vencedor en las hazañas bélicas, triunfador en la vida social y política, fracasa en lo que quizás deseaba más íntimamente que era la consecución del amor. No olvidemos que los amores contrariados también forman parte de la vida de los héroes, y que tampoco ellos son dueños de su propio destino.

\footnotetext{
${ }^{18}$ R. Dozy: Ibid, p. 214, vol III
} 
